DOI: http://dx.doi.org/10.11606/issn.1984-4867.v26i4p903-918

\title{
Gestão Familiar no Agroturismo em Santa Catarina: a experiência da Acolhida na Colônia ${ }^{1}$
}

\section{Family Management in the Agritourism in Santa Catarina: the case of Acolhida na Colônia}

\section{Gestión Familiar em Agroturismo em Santa Catarina: la experiencia de la Acolhida na Colônia}

\author{
Anandra Gorges Martendal ${ }^{2}$ \\ Marialva Tomio ${ }^{3}$
}

\begin{abstract}
Resumo
O objetivo desta pesquisa foi analisar a gestão familiar das propriedades rurais ligadas a Associação de Agroturismo Acolhida na Colônia. O método utilizado foi a abordagem qualitativa, com delineamento exploratório, aplicando-se a pesquisa em duas propriedades selecionadas de acordo com o perfil pré-estabelecido. Os resultados da pesquisa mostram que a gestão das propriedades pesquisadas é familiar e ocorre de forma não profissionalizada. Constatou-se a ausência de sistemas formais de atuação relacionados às funções administrativas: o planejamento é informal e adequado de acordo com as necessidades e a disponibilidade de recursos financeiros; a organização do trabalho é determinada pelo gênero, os afazeres domésticos são direcionados às mulheres e o trabalho externo à casa é direcionado aos homens; o provimento de recursos humanos é familiar e a ajuda de terceiros nas atividades da propriedade é eventual; o processo decisório é baseado nas deliberações conjuntas da família; os membros da família estão, notavelmente, comprometidos com a execução das tarefas cotidianas; e, os registros referentes às receitas, despesas e a movimentação turística nas propriedades não são lineares.
\end{abstract}

Palavras-chave: Gestão Familiar; Agroturismo; Acolhida na Colônia.

\begin{abstract}
The objective of this research was to analyze the Family management on farms linked to Associação de Agroturismo Acolhida na Colonia. The method used was the qualitative approach with exploratory design, using the case study and applying the research in two
\end{abstract}

\footnotetext{
1 Trabalho apresentado e publicado nos Anais do XII Seminário ANPTUR realizado em Setembro de 2015 na cidade de Natal-RN.

${ }^{2}$ Mestre em Administração pela Universidade Regional de Blumenau. Formada em Administração, com ênfase em Comércio Exterior, pela UNIDAVI. Blumenau-SC, Brasil. E-mail: amartendal@gmail.com.

3 Docente do Programa de Mestrado em Administração pela Universidade Regional de Blumenau. Pósdoutorado em Administração pela Universidade Federal do Rio Grande do Sul (EA/UFRGS). Doutora em Engenharia de Produção pela Universidade Federal de Santa Catarina (UFSC). Blumenau-SC, Brasil. E-mail: marialva@furb.br.
} 
selected properties according to the pre-established profile. The research results show that the management of the properties is familiar and is not professionalized form. It was found the absence of formal actuation systems related to administrative functions: planning is informal and appropriate according to the needs and the availability of financial resources; the organization of work is determined by gender, housework are targeted to women and external work to the house is directed to men; the provision of human resources is family and the help of others in the activities of property is possible; decision-making is based on joint deliberations of the family; family members are, notably, committed to carrying out everyday tasks; and records relating to revenues, expenses and the tourist movement in the properties are not linear.

Keywords: Family management; Agritourism; Acolhida na Colônia.

\section{Resumen}

El objetivo de esta investigación fue analizar las propiedades rurales familiares conectados a la Associação de Agroturismo Acolhida na Colônia. El método utilizado fue el enfoque cualitativo con un diseño exploratorio, la aplicación de la investigación en dos propiedades seleccionadas de acuerdo al perfil preestablecido. Los resultados de la investigación muestran que la administración de las propiedades es familiar y no profesionalizada. Se la ausencia de sistemas de actuación formales relacionados con las funciones administrativas: planificación es informal y adecuado en función de las necesidades y la disponibilidad de recursos financieros; la organización del trabajo está determinada por el género, las tareas domésticas están dirigidos a las mujeres y el trabajo externo a la casa se dirige a los hombres; la provisión de recursos humanos es la familia y la ayuda de otras personas en las actividades de la propiedad es posible; la toma de decisiones se basa en las deliberaciones conjuntas de la familia; miembros de la familia, en particular, se comprometieron a llevar a cabo las tareas cotidianas; y el registro de los ingresos, los gastos y el movimiento turístico en las propiedades no son lineales.

Palabras-clave: Gestión Familiar; Agriturismo; Acolhida na Colônia.

\section{Introdução}

O turismo, em pequenas propriedades rurais, figura como uma alternativa de empregos rurais não agrícolas e pode ajudar a valorizar o modo de vida no campo e gerar complementação de renda para os agricultores familiares. As pequenas cidades têm potencial turístico, elas são procuradas por pessoas que estão em busca da natureza, bucolismo, tranquilidade, ou seja, tudo aquilo que é oposto ao urbano, assim, a atividade turística ganha papel de destaque como uma estratégia de desenvolvimento para espaços rurais, em especial para os pequenos municípios que têm na agricultura a base da sua economia (Tulik, 2003). 
É nesse sentido que atua a Associação de Agroturismo Acolhida na Colônia, no despertar para a utilização do potencial turístico da propriedade rural, possibilitando incremento da renda para as pessoas que vivem da agricultura, estimulando-as a diversificarem sua produção e a permanecerem no campo. O projeto tem como um dos seus princípios norteadores manter o meio rural vivo, oferecendo perspectivas para os seus jovens (Estatuto Acolhida na Colônia, 1999). A Associação favorece a cooperação entre agricultores e fomenta o intercâmbio de informações e experiências entre eles (Fortunato; Teixeira, 2011).

A gestão familiar desses pequenos empreendimentos é o ponto de interesse deste artigo. De acordo com Bornholdt (2005) uma família de agricultores também pode ser definida como uma empresa familiar, pois são famílias empresárias que mantêm um negócio e essas famílias, por cultura e tradição podem se destacar em termos econômicos, financeiros e sociais. A gestão familiar envolve uma relação entre as variáveis família, propriedade e empresa/gestão (Floriani, 2008), equacionar esses fatores e obter resultados satisfatórios, inevitavelmente, é trabalho para um bom administrador. Portanto, analisar a gestão familiar das propriedades rurais que integram a Associação de Agroturismo Acolhida na Colônia, em Santa Catarina, é o objetivo desta pesquisa.

\section{Agroturismo}

A atividade turística é multifacetada e multidimensional, ela envolve várias pessoas e diferentes atividades econômicas, refletindo sua complexidade e a dificuldade de criar uma base teórica coerente. Por isso, aceita várias definições, e o que se percebe é a falta de coerência entre elas (Cooper et al., 2001). Apesar dos esforços empreendidos para uniformizar as classificações de diferentes tipos de turismo, isso ainda não aconteceu, pois as formas de praticar turismo se misturam e, por isso, um conceito aplicado a uma dessas formas pode servir para definir outras (Tulik, 2003). Além disso, os seres humanos, enquanto seres sociais multifacetados, não são passíveis de enquadramentos rígidos, e em sua maioria, praticam mais de um tipo de turismo ao mesmo tempo (Baretto; Rejowski, 2009). 
O mercado turístico tem diferentes tipos de turismo, o setor tem experimentado uma forte segmentação, com o estabelecimento crescente de novos nichos de mercado (Queiroz, 2009). Nessa atividade, as maiores probabilidades de sucesso são aquelas que estão em concordância com as fortes tendências, por isso, é necessário observar as mudanças de mercado e as necessidades e direcionamentos da demanda turística (Panosso Netto; Ansarah, 2009).

Uma dessas tendências é a de valorização dos aspectos ambientais, que surge atrelada a uma consciência ecológica que incentiva a busca por ambientes mais limpos, belos, verdes, e longe do concreto cinza urbano. Logo, o turismo praticado na natureza é um dos segmentos mais significativos dos últimos anos em todo o mundo, em especial, o turismo no espaço rural (Queiroz, 2009), que tem nos costumes, na tradição e na identidade local, recursos endógenos que integram a experiência rural, cada vez mais procurada por turistas (Carvalho; Lima; Kastenholz, 2014).

Contudo, os limites entre rural e urbano não são claros, porque certos espaços urbanos preservam características tipicamente rurais, e certas funções urbanas como indústrias e serviços, dentre os quais o turismo, chegaram ao espaço rural, gerando postos de trabalho não agrícolas no meio rural (Tulik, 2003). A diversidade na utilização dos termos área, espaço, zona e meio rural resulta em expressões como turismo no espaço rural, turismo nas áreas rurais, na zona rural e no meio rural -, ocasionando o uso aleatório, sem qualquer preocupação com o significado desses termos.

Os conceitos de turismo no meio rural e turismo rural são muitas vezes confundidos. Nesse sentido, cabe destacar que o turismo no meio rural refere-se, de forma abrangente, a todas as atividades realizadas no meio rural (Campanhola; Silva, 2000), inclusive aquelas que não estão ligadas ao conteúdo rural (Tulik, 2003). Já o turismo rural consiste no conjunto de atividades desenvolvidas no espaço rural, que estejam ligadas às características próprias do meio rural como, a paisagem, o estilo de vida e a cultura rural (Tulik, 2003), ou seja, são atividades que tem como base a produção agropecuária, agregando valor aos seus produtos e serviços, resgatando e 
promovendo o patrimônio cultural e natural da comunidade (Ministério do Turismo, 2014).

Na mesma linha de confusão de conceitos está o agroturismo. Para alguns autores, como Campanhola e Silva (2000), turismo rural e agroturismo são apresentados como sinônimos, assim como em alguns países europeus, como a Espanha, onde não se distingue turismo rural de agroturismo (Tulik, 2003). Por outro lado, há autores como Oxinalde (1994) que afirmam que, muitas vezes se confunde turismo rural com agroturismo, e que as diversas modalidades turísticas - como o turismo rural, o turismo verde, o ecoturismo, o agroturismo, o turismo cultural, e o turismo alternativo - estão compreendidas no Turismo no Espaço Rural, e que tais modalidades não se excluem, mas se complementam. Nesse mesmo sentido, Guzzatti (2011) afirma que o agroturismo é um segmento do turismo rural.

Sendo assim, o turismo no espaço rural engloba diversas modalidades, entre elas o turismo rural e o agroturismo. De acordo com Tulik (2003) o agroturismo desenvolve-se integrado a uma propriedade rural ativa, de organização e gestão familiar, com a presença do proprietário, como forma complementar de atividades e de renda, e pressupõe o contato direto do turista com o meio rural, com alojamento na propriedade e a possibilidade de participar das atividades cotidianas. Enfatiza-se que, no agroturismo, as atividades são desenvolvidos de forma incremental, a partir dos recursos já existentes na propriedade, mantendo fortes ligações com a tradição e a cultura (Brandth; Haugen, 2011).

Os conceitos de turismo em áreas rurais, turismo rural e agroturismo a serem utilizados para nortear este artigo estão de acordo com as definições de Oxinalde (1994), Guzzatti (2011) e Tulik (2003), ou seja, o turismo nas áreas rurais compreende todas as manifestações turísticas que acontecem no espaço rural, independentemente de estarem ligadas ou não à produção agrícola; o turismo rural está diretamente ligado às manifestações turísticas que tem a ver com a rotina, os hábitos e costumes da roça; e o agroturismo, por sua vez, é aquele que se desenvolve em propriedades rurais ativas e de gestão familiar, na qual o turista compartilha das atividades e rotinas da propriedade, e interage com o agricultor e sua família.

\subsection{Gestão familiar da propriedade rural}


As propriedades rurais podem ser classificadas, de acordo com Veiga (2001), em propriedades patronais e propriedades familiares. Cada um dos modelos apresenta características distintas em relação à gestão, ao trabalho, ao nível de especialização, a atividade produtiva, enfim, características específicas para cada modelo, descritas em detalhes no quadro que segue:

Quadro 1 - Características da propriedade patronal e da propriedade familiar

\begin{tabular}{|l|l|}
\hline \multicolumn{1}{|c|}{ Propriedade Patronal } & \multicolumn{1}{c|}{ Propriedade Familiar } \\
\hline - Completa separação entre gestão e & - Trabalho e gestão intimamente ligados; \\
trabalho; & - Direção do processo produtivo diretamente \\
- Organização centralizada; & assegurada pelos proprietários ou arrendatários; \\
- Ênfase na especialização; & - Ênfase na diversificação; \\
- Ênfase nas práticas padronizáveis; & - Ênfase na durabilidade dos recursos e na \\
- Predomínio do trabalho assalariado; & qualidade de vida; \\
- Tecnologias dirigidas à eliminação das & - Trabalho assalariado complementar; \\
decisões de terreno e de momento. & - Decisões imediatas, adequadas ao alto grau de \\
& imprevisibilidade do processo produtivo. \\
\hline
\end{tabular}

Fonte: VEIGA, 2001.

A agricultura de propriedade familiar se caracteriza por estabelecimentos nos quais os meios de produção pertencem à família, e o trabalho é exercido pelos proprietários em uma área relativamente pequena ou média (Marafon, 2006). Em uma propriedade rural os custos de produção, a oscilação dos preços, as doenças nos rebanhos, as pragas na plantação, os fatores climáticos, a natureza do produto, geralmente perecível, e a sazonalidade da produção são fatores que influenciam nas atividades da propriedade. Lidar com todos esses fatores, e conseguir um bom resultado, é trabalho para um administrador competente (Avila; Avila; Ferreira, 2003).

A administração rural é um ramo da ciência administrativa que cuida da análise econômica das culturas e criações, dos registros de dados contábeis e técnicos, e da análise dos custos de produção (Avila; Avila; Ferreira, 2003). Por isso, é interessante resgatar as funções administrativas, para subsidiar a discussão e entender melhor os passos básicos do processo administrativo. Entre as funções que cabem ao administrador estão: planejar, organizar, prover recursos humanos, liderar, coordenar e controlar. A seguir descrevem-se as ações envolvidas em cada uma delas:

- Planejar significa pensar antecipadamente naquilo que se deseja alcançar, e determinar os meios e recursos para concretizar esse desejo (Vijayakumar, 2009). Esta função envolve coletar informações e diagnosticar a situação; 
estabelecer objetivos e metas; estabelecer políticas e procedimentos, de acordo com os objetivos para orientar as decisões; elaborar e implantar planos para alcançar as metas, e estabelecer cronogramas para acompanhar a sua execução (Lacombe; Heilborn, 2003).

- Organizar se refere a coletar e alocar os recursos necessários para alcançar os objetivos da organização (Vijayakumar, 2009). Essa função envolve os processos de identificar, dividir e alocar o trabalho a ser realizado. $\mathrm{O}$ administrador precisa definir responsabilidades e autoridade, e estabelecer as relações entre os grupos, de modo a possibilitar que as pessoas trabalhem eficazmente para atingir os objetivos (Lacombe; Heilborn, 2003).

- Prover recursos humanos é formar uma equipe competente, integrada, motivada e disposta a agir para o conjunto. Nesta função está incluído saber recrutar, selecionar e treinar pessoas capazes de colaborar para atingir os objetivos da empresa (Lacombe; Heilborn, 2003).

- Liderar é influenciar o comportamento individual, ou do grupo (Vijayakumar, 2009), a fim de atingir os objetivos e as metas de interesse comum. O administrador deve ser capaz de alcançar os objetivos empresariais, por meiodos seus liderados e, para isso, conforme o liderado e a ocasião, age de forma diferente: ordena, comanda, persuade, motiva, compartilha dificuldades, delega tarefas, cobra resultados, alterando a forma de agir de acordo com cada situação ou tipo de liderado (Lacombe; Heilborn, 2003).

- Coordenar significa cooperar com todas as demais unidades da organização para que as atividades sejam executadas de forma balanceada. Nessa função as atividades devem ser executadas na quantidade correta e de forma sincronizada, ou seja, no momento certo e de forma integrada, o que significa ir na direção correta (Lacombe; Heilborn, 2003).

- Controlar envolve o processo de verificação entre aquilo que foi planejado, e o que, de fato se concretizou (Vijayakumar, 2009). O controle assegura que as atividades da organização a levam na direção dos objetivos estabelecidos. Essa função envolve medir o desempenho, comparando-o com o desejado e, 
caso seja necessário, envolve também aplicar medidas corretivas (Lacombe; Heilborn, 2003).

No caso das propriedades rurais familiares existem particularidades a serem apontadas. A gestão geralmente é familiar, e está intimamente relacionada ao trabalho, logo, o proprietário além de planejar o que deve ser feito, também executa as tarefas. Além disso, a gestão familiar envolve variados aspectos de complicada equação, é uma relação entre as variáveis família/ propriedade e empresa/gestão. Liderar ao mesmo tempo a família e os negócios tem pesos diferentes entre o fundador e os seus sucessores e, a cada geração pode mudar a maneira de comandar (Floriani, 2008).

Todos esses fatores, acima citados, são pormenores relacionados à gestão familiar destas propriedades, mas que não diminuem a importância da presença de todas as funções administrativas no processo administrativo, porque uma família de agricultores também pode ser definida como uma empresa familiar, pois eles não deixam de ser empresários que mantêm um negócio (Bornholdt, 2005).

\section{Metodologia}

A metodologia proposta para a realização desta pesquisa tem delineamento exploratório, método qualitativo e considerou duas propriedades rurais participantes do projeto da Associação de Agroturismo Acolhida na Colônia, no estado de Santa Catarina. O perfil das propriedades foi previamente estabelecido de acordo com os seguintes critérios: ser uma propriedade participante da Associação de Agroturismo Acolhida na Colônia; estar situada no estado de Santa Catarina (Brasil); estar apta a receber turistas; e, ser uma propriedade com constituição familiar específica, isto é, administrada por uma família.

A partir desses critérios foram escolhidas duas propriedades: uma que ingressou na Associação durante o projeto-piloto, a Pousada Doce Encanto, situada no município de Santa Rosa de Lima; e a outra, que ingressou no plano de expansão da Associação, o Sítio Colina, situada no município de Presidente Nereu. Os dados para a pesquisa foram coletados a partir do site institucional da Associação de Agroturismo Acolhida na Colônia e do seu Estatuto, e por meio de pesquisa 
bibliográfica e de visitas técnicas realizadas no mês de janeiro de 2015, nas duas propriedades participantes, que proporcionaram a oportunidade de aplicação das entrevistas baseadas em um roteiro pré-definido. Os entrevistados foram os proprietários de cada uma das propriedades selecionadas.

A coleta de dados envolveu também a observação, e conversas informais com os proprietários e seus familiares durante as visitas técnicas. Os dados obtidos a partir das entrevistas, foram gravados em áudio, e posteriormente foi realizada a transcrição literal. Os dados obtidos a partir da observação e das conversas informais, foram registrados em notas de campo. Não foi possível obter dados secundários nas propriedades, porque os proprietários não possuem registros lineares da movimentação turística, de receitas ou despesas, nem de processos ou rotinas de trabalho.

\section{Resultados}

A Associação de Agroturismo Acolhida na Colônia é uma sociedade civil, sem fins lucrativos, criada em 1999, em Santa Catarina, com sede no município de Santa Rosade Lima. Ela é inspirada no modelo francês Accueil Paysan, que atua na França desde 1987 (Acolhida na Colônia, 2015). A associação brasileira estabeleceu uma parceria formal com a entidade francesa, passando a integrar a rede Accueil Paysan, que concedeu o direito de uso da marca no Brasil (Guzzatti, 2010). A proposta da Associação de Agroturismo Acolhida na Colônia direciona-se para uma experiência turística comprometida com a ética, a solidariedade, o meio ambiente e a manutenção da produção rural. Nesse segmento, os ganhos não são contabilizados por lucros ou dividendos, mas por indicadores como geração de renda, inclusão social e manutenção das tradições e costumes (Fortunato \& Teixeira, 2011).

Para fazer parte da Associação de Agroturismo Acolhida na Colônia, os agricultores familiares devem se mostrar dispostos a seguir a filosofia, os princípios técnicos e as práticas de agroturismo que estão de acordo com o Estatuto da Associação, com o Regimento Interno, e com o Caderno de Normas e Encargos da mesma. As atividades oferecidas nas propriedades associadas compreendem: restaurante colonial; pousada, café e quartos coloniais; agroindústria familiar; armazém da 
colônia; passeio a cavalo; trilhas; banho de cachoeira ou de rio; educação ambiental; agroecologia; e programação para crianças (Acolhida na Colônia, 2015).

As duas propriedades, que fazem parte da pesquisa, foram selecionadas entre 93 propriedades, ao todo, com base nos critérios previamente estabelecidos e descritos em detalhes na metodologia. A Propriedade Sítio Colina está situada na Regional de Ibirama, na cidade de Presidente Nereu, na localidade chamada Rio Bandeira, próxima $6 \mathrm{~km}$ do centro da cidade. O município tem uma área de $225.661 \mathrm{~km}^{2}$, e, em 2010, tinha uma população de 2.284 habitantes, sendo 1.476 residentes na área rural, e 808 residentes na área urbana do município.

O cultivo de tabaco era a principal atividade desenvolvida na propriedade, antes de seus proprietários associarem-se à Acolhida na Colônia, no ano de 2007. Atualmente, as atividades incluem a plantação de legumes e verduras para feira, e a criação de gado e de equinos. As atividades ligadas ao agroturismo, e oferecidas aos visitantes são: a pousada, com 16 leitos, as refeições, as trilhas e a cachoeira, camping, pesque e pague, e passeios a cavalo. Toda a estrutura disponível aos visitantes foi adaptada a partir das instalações já existentes. O galpão, que servia para abrigar e alimentar as vacas leiteiras, virou ambiente de convivência dos turistas, e o paiol de armazenamento de tabaco foi transformado em quartos para os visitantes.

A pousada Doce Encanto fica na região das Encostas da Serra Geral, no município de Santa Rosa de Lima, na localidade denominada Rio dos Índios, a cerca de $4 \mathrm{~km}$ do centro da cidade. O município de Santa Rosa de Lima dista aproximadamente 124 km de Florianópolis, tem uma área de 202.004 km² e, em 2010, tinha uma população de 2.065 habitantes, sendo 1.547 residentes na área rural, e 518 residentes na área urbana do município.

Os proprietários se associaram à Acolhida na Colônia, em 1999. Antes disso, o plantio de tabaco ocupava as terras, juntamente com outros cultivos, e também a produção de carvão vegetal. Atualmente, as atividades agropecuárias desenvolvidas compreendem a plantação de árvores frutíferas, a criação de gado e ovinos, e a produção na agroindústria de derivados da cana da família. As atividades ligadas ao agroturismo, compreendem: a pousada, com 22 leitos, as trilhas, o banho de rio e de cachoeira, as refeições, as lições em agroecologia para os visitantes, e a agroindústria 
da família. Da estrutura antiga da propriedade, a estufa de tabaco foi aproveitada e transformou-se em pousada, o paiol de tabaco virou espaço de convivência, e a casa dos proprietários foi ampliada, para atender ao aumento na demanda de hóspedes.

As propriedades visitadas são tipicamente propriedades rurais familiares, e têm características descritas na literatura como sendo próprias desse tipo de negócio familiar, ou seja, os meios de produção pertencem à família, e o trabalho é exercido pelos proprietários em uma área relativamente pequena ou média (Marafon, 2006). Além disso, o trabalho e a gestão estão intimamente ligados; a direção do processo produtivo é diretamente assegurada pelos proprietários; existe ênfase na diversificação; ênfase na durabilidade dos recursos e na qualidade de vida; trabalho assalariado complementar e; decisões imediatas, adequadas ao alto grau de imprevisibilidade do processo produtivo (Veiga, 2001).

Observou-se a presença das funções administrativas de planejamento, organização, provimento de recursos humanos, liderança, coordenação e controle, descritas na literatura por Lacombe e Heilborn (2003), e desempenhadas de maneira informal nas propriedades em estudo. O único norteador formal das atividades é o Caderno de Normas da Associação de Agroturismo Acolhida na Colônia, conforme relata a proprietária do Sítio Colina, "a única coisa que a gente tem é o caderno de normas, que nós temos que seguir". Este caderno estabelece os procedimentos, para concessão da licença de uso do selo da referida Associação, e regulamenta a oferta de alimentação, hospedagem, venda de produtos e atividades de lazer na colônia, mas em nenhum momento regulamenta a gestão.

Nas duas propriedades, o processo de tomada de decisões é feito em conjunto, pois é a família que decide o que será feito, e quais os rumos serão dados à propriedade. Ele ocorre a partir das conversas entre os familiares, que após debaterem sobre o assunto em questão, chegam ao consenso do que será feito e como será feito, contudo, o papel de liderança nas propriedades estudadas é exercido, implicitamente, pelo casal de proprietários, ou por um deles.

Ao abordar o tema planejamento nas entrevistas, percebeu-se que os proprietários sabem o que desejam para o futuro da propriedade, contudo, não possuem nenhum registro, nem daquilo que já foi feito, nem daquilo que ainda pretendem fazer. Ao 
falar do assunto, a proprietária do Sítio Colina afirma que os planos "A gente tem na cabeça". Percebeu-se, que os planos para o futuro apresentam contornos bem definidos, contudo, não parece existir nenhum comprometimento em relação a prazos, ou expectativas em relação aos recursos necessários para a execução dos mesmos.

Portanto, não existe nenhum planejamento formalizado, tampouco metas, objetivos ou prazos estabelecidos. Existem apenas as prioridades eleitas em cada propriedade. No entanto, a incerteza quanto aos recursos financeiros, é uma característica marcante e parece influenciar nas decisões a serem tomadas, pois os proprietários estão acostumados a aguardar para executar os planos, conforme a disponibilidade de recursos financeiros, pois prezam pela segurança, é o que afirma o proprietário da Pousada Doce Encanto, "plano a gente tem, vai fazendo o que que é possível, né!"

As duas propriedades pesquisadas, em sua organização, apresentam uma divisão de trabalho determinada pelo gênero. Em geral, as mulheres ficam encarregadas da operacionalização do trabalho doméstico, como fazer comida e cuidar da limpeza da casa e da horta. Os homens concentram suas atividades na parte externa à casa, no feitio de cercas, no trabalho da roça, ou então, na construção e ampliação das estruturas da propriedade.

Na área de recursos humanos, toda a mão de obra necessária é suprida pela família e, eventualmente, são contratadas outras pessoas para colaborar nas atividades nos dias de maior movimento, e para auxiliar em outras demandas da propriedade. A proprietária do Sítio Colina expressa, em sua fala, que os três filhos, que moram na propriedade, ajudam "a atender, ajudam no serviço que precisar". Na Pousada Doce Encanto, os familiares ajudam a guiar grupos, fazer reservas, divulgar a propriedade nas redes sociais, efetuar serviços de limpeza, etc. Percebeu-se que todos os familiares se mostram comprometidos com a execução das tarefas das respectivas propriedades.

O controle das contas, e a avaliação dos resultados, não é um hábito para os associados, que não possuem nenhum tipo de registro constante e organizado de receitas, de despesas, nem da movimentação de turistas durante o mês ou o ano, como também não há registro de balanços feitos ao final de períodos determinados, 
para avaliar os resultados das atividades desenvolvidas. A proprietária do Sítio Colina diz que, "enquanto que a gente tá dando conta de pagar, de certo não tá no vermelho", e o proprietário da Pousada Doce Encanto afirma que, "por enquanto tá meio assim [desleixado], por isso que tá nessa bagunça de não saber quantas pessoas passam [...] cada um tem a sua formazinha de tocar, de controlar, como é em qualquer propriedade familiar."

\section{Conclusão}

As propriedades estudadas apresentam características descritas na literatura que são próprias de propriedades rurais familiares, pois, os meios de produção pertencem à família, as decisões são tomadas pela família na medida em que aparecem as questões a serem resolvidas, a gestão e o trabalho estão intimamente relacionados e a ênfase da atividade produtiva está na diversificação. Observou-se que a gestão das duas propriedades em estudo é familiar e, além disso, a gestão é empírica e não profissionalizada, os agricultores dedicam-se ao trabalho pesado e deixam a formalização das atividades de lado.

$\mathrm{Na}$ gestão das propriedades em estudo observou-se que o planejamento não é registrado pelos respectivos proprietários ou familiares, somente em casos excepcionais os planos são formalizados. Também não foram encontradas, nas propriedades pesquisadas, ferramentas de controle das atividades desenvolvidas, tais como registros de acompanhamento de atividades, balanços, etc. O trabalho é alocado, geralmente, de acordo com o gênero ou conforme a disponibilidade de cada membro da família, contudo essa divisão é flexível, e permite que qualquer membro da família desempenhe determinada atividade, que inicialmente era de responsabilidade de outrem. As necessidades de mão de obra são supridas, na maior parte do tempo, pela própria família e a ajuda de terceiros nas tarefas da propriedade é eventual.

O trabalho e a gestão caminham paralelamente nas propriedades estudadas, por isso, o casal e os filhos trabalham e decidem conjuntamente, contudo, percebeu-se que existe um hierárquico dentro da família, refletido pela cultura de respeito aos genitores, situação na qual o casal ou um dos cônjuges ocupam o lugar de liderança 
nata. A coordenação das atividades é influenciada pela posse dos meios de produção, quer seja na flexibilidade da distribuição do trabalho, quer seja no comprometimento dos membros da família em relação à execução das tarefas, sendo assim, todos os membros da família estão dispostos a desempenhar qualquer atividade na propriedade.

O cotidiano das famílias visitadas é cheio de afazeres, o trabalho na roça e na casa é árduo e a rotina descrita é cansativa, porém, a questão financeira foi a que mais se destacou durante as entrevistas ao falar de desafios. Os proprietários se mostraram cautelosos com os planos para o futuro e com os investimentos a serem dispendidos para realizá-los, eles evitam fazer planos sem garantia de que terão recursos para executá-los.

É nesse sentido que as políticas governamentais aparecem como oportunidades para a melhoria e ampliação da estrutura das propriedades, pois sem esses recursos, talvez os agricultores tivessem que aguardar algum tempo até se capitalizarem, para então realizar as melhorias, o que impossibilitaria a ampliação dos negócios a curto prazo. Com o apoio do governo, em nível estadual e federal, eles conseguem aumentar a sua capacidade de empreender e conseguem colher os frutos do agroturismo num espaço menor de tempo.

Existe um potencial de demanda a ser explorado pelas propriedades pesquisadas, pois o turismo no espaço rural, se apresenta como um segmento significativo da atividade turística, com tendência de valorização e crescimento. Por isso, os proprietários estão diante de uma conjuntura favorável no cenário mundial e, têm localmente, o apoio da Acolhida na Colônia, que fomenta as atividades relacionadas ao agroturismo, juntamente com a proposta de valorização da cultura rural e preservação ambiental. No entanto, os proprietários poderiam dar mais atenção à necessidade de uma gestão profissional e formalizada, colocando de lado a resistência percebida, durante a pesquisa, em aderir a esse tipo de procedimento, e colaborando com os esforços que a Associação tem empreendido nesse sentido.

Como sugestão de melhoria, para a gestão das propriedades, aponta-se para a o aprimoramento e formalização do processo de gestão das propriedades, pautado em elementos como planejamento, controle e organização. São medidas que não exigem 
investimentos significativos por parte dos proprietários, apenas dedicação, atenção e comprometimento. Os registros das atividades poderiam servir de base para estabelecer estatísticas, apoiar decisões futuras sobre ampliação e melhorias, elaborar planejamentos a nível de propriedade e a nível de Associação, estabelecer posicionamento no mercado, justificar a busca de recursos governamentais e demonstrar a importância da atividade de agroturismo para as famílias e para a região.

Para ampliar e aprofundar os estudos científicos na área da gestão familiar no agroturismo, sugere-se pesquisar o tema em propriedades rurais ligadas a associações de agroturismo que atuem em outras regiões do país. Recomenda-se, também, analisar de que maneira as atividades de agroturismo têm influenciado, efetivamente, aspectos econômicos, sociais e ambientais, tanto na área de abrangência da Associação de Agroturismo Acolhida na Colônia, quanto nas áreas de atuação de outras associações desse gênero. As pesquisas futuras podem pautar-se nos seguintes pressupostos: geração de renda pelo agroturismo; contribuição dessa atividade para a permanência dos agricultores em suas propriedades rurais; e a contribuição da atividade para a preservação do meio ambiente.

\section{Referências}

ACOLHIDA NA COLÔNIA. Disponível em: 〈http://www.acolhida. com.br>. Acesso em: 06 jan. 2015.

. Estatuto da Associação de Agroturismo Acolhida na Colônia. Santa Rosa de Lima, 1999.

AVILA, Mario Lúcio de; AVILA, Silvia Starling Assad de; FERREIRA, Cleone José. Administração rural: elementos de estudo na fazenda córrego da liberdade no município de Ipiranga de Goiás. Revista Eletrônica da Ciência Administrativa- RECADM, v. 1 n. 2, nov. 2003.

BARRETO, Margarita; REJOWSKI, Mirian. Considerações epistemológicas sobre segmentação: das tipologias turísticas à segmentação de mercado. In: PANOSSO NETTO, Alexandre; ANSARAH, Marília Gomes dos Reis (orgs.). Segmentação do mercado turístico. São Paulo: Manole, 2009.

BORNHOLDT, Werner. Governança na empresa familiar. Porto Alegre: Bookman, 2005.

BRANDT, Berit; HAUGEN, Marit S. Farm diversification into tourism: implications for a social indentity? Journal of rural studies, v. 27, p. 34-44, 2011.

CAMPANHOLA, Clayton; SILVA, José Graziano da. O agroturismo como nova fonte de renda para o pequeno agricultor brasileiro. In: ALMEIDA, Joaquim Anécio; RIEDL, Mário. Turismo Rural: ecologia, lazer e desenvolvimento. Bauru: EDUSC, 2000. 
CARVALHO, Mariana Souza; LIMA, Joana; KASTENHOLZ, Elizabeth. Criatividade Cultural: que oportunidade para destinos rurais? Passos Revista de Turismo y Patrimonio Cultural, v. 12, n. 3, p. 635-648, 2014.

COOPER, Chris, et al. Turismo, princípios e prática. 2. ed. Tradução de Roberto Cataldo Costa. Porto Alegre: Bookman, 2001.

FLORIANI, Oldoni Pedro. Empresa familiar ou inferno familiar. 2. ed. Curitiba: Juruá, 2008.

FORTUNATO, Rafael Ângelo; TEIXEIRA, Kelly Lima. A gestão do conhecimento na organização do turismo rural nas Encostas da Serra Geral - SC: o caso do projeto Acolhida na Colônia. In: Seminário da Associação Nacional Pesquisa e Pós-Graduação em Turismo - ANPTUR, 8, 2011, Balneário Camboriú/SC. Anais..., 2011.

GUZZATTI, Thaise Costa. O agroturismo como elemento dinamizador na construção de territórios rurais: o caso da Associação de Agroturismo Acolhida na Colônia em Santa Rosa de Lima (SC). 2010. $281 \mathrm{f}$. Tese (Doutorado em Geografia) - Programa de pós-graduação em Geografia, Universidade Federal de Santa Catarina, Florianópolis, 2010.

; TURNES, Valério Alécio. O papel da Associação de Agroturismo Acolhida na Colonia (SC) na construção de políticas públicas de turismo focadas no desenvolvimento rural e na promoção da agricultura familiar. In: Encontro Nacional de Pesquisadores em Gestão Social, 5, 2011, Florianópolis. Anais... Florianópolis, 2011, p. 1-19.

LACOMBE, Francisco José Masset; HEILBORN, Gilberto Luiz José. Administração: princípios e tendências. São Paulo: Saraiva, 2003.

MARAFON, Gláucio José. Agricultura familiar, pluriatividade e turismo: reflexões a partir do território fluminense. Revista de Geografia Agrária, v. 1, n. 1, p. 17-60, fev. 2006.

MINISTÉRIO DO TURISMO. Marcos Conceituais. Disponível em: < http://www.turismo.gov.br/export/sites/default/turismo/o ministerio/publicacoes/downloads publicac oes/Marcos_Conceituais.pdf>. Acesso em: 20 nov. 2014.

OXINALDE, Miguel Del Reguero. Ecoturismo: nuevas formas de turismo en el espacio rural. Barcelona: Bosch Turismo, 1994.

PANOSSO NETTO, Alexandre; ANSARAH, Marília Gomes dos Reis. Segmentação em turismo: panorama atual. In: PANOSSO NETTO. Alexandre; ANSARAH, Marília Gomes dos Reis (orgs.). Segmentação do mercado turístico. São Paulo: Manole, 2009.

QUEIROZ, Odaléia Telles Marcondes Machado. Turismo Paisagístico. In: PANOSSO NETTO. Alexandre; ANSARAH, Marília Gomes dos Reis (orgs.). Segmentação do mercado turístico. São Paulo: Manole, 2009.

TULIK, Olga. Turismo Rural. São Paulo: Aleph, 2003.

VEIGA, José Eli da. O Brasil rural precisa de uma estratégia de desenvolvimento. Convênio FIPEIICA (MDA/CNDRS/NEAD), Brasília, 2001.

VIJAYAKUMAR, Uma. Top Management Control Functions for Information Systems in Small and Medium Enterprises. Informatica Economica, v. 13, n. 4, p.109-115, 2009.

\section{Recebido em: 17/11/2015}

Aprovado em: 12/12/2015 